\title{
PUBLIC HEALTH SURVEILLANCE OF INFECTIONS AND BEHAVIOURAL RISK FACTORS LIKE POOR SANITATION IN A CHANGING ENVIRONMENT
}

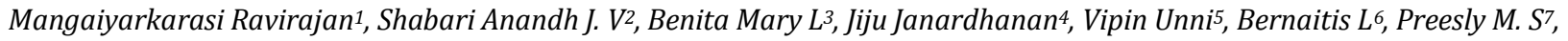 \\ Revathi P. Shenoy ${ }^{8}$ \\ ${ }_{1}^{1}$ Senior Scientist, UGC Fellow, Central Inter Disciplinary Research Facility, Sri Balaji Vidhyapeeth University, Pondicherry. \\ ${ }^{2}$ Tutor, Department of Pharmacology, Mahatma Gandhi Medical College and Research Institute, Pondicherry. \\ ${ }^{3}$ Postgraduate Student, Department of Physiology, Kasturba Medical College, Manipal Academy of Higher Education, Manipal, \\ Karnataka. \\ ${ }^{4}$ Lecturer Department of Microbiology, Co-operative Institute of Health Sciences, Thalassery, Kerala. \\ ${ }^{5}$ Lecturer, Department of Microbiology, Ratnavel Subramaniam (RVS) Dental College and Hospital, Kumaran Kottam Campus, \\ Coimbatore, Tamilnadu. \\ ${ }_{6}^{6}$ Lecturer, Department of Microbiology, Ratnavel Subramaniam (RVS) Dental College and Hospital, Kumaran Kottam Campus, \\ Coimbatore, Tamilnadu. \\ ${ }^{7}$ Lecturer, Department of Biostatistics, Ratnavel Subramaniam (RVS) Siddha Medical College and Hospital, Kumaran Kottam Campus, \\ Coimbatore, Tamilnadu. \\ ${ }^{8}$ Associate Professor, Department of Biochemistry, Kasturba Medical College, Manipal Academy of Higher Education, Manipal, \\ Karnataka.
}

ABSTRACT
BACKGROUND
Public health surveillance is a continuous, systematic collection, analysis and interpretation of health-related data needed for the
planning, implementation and evaluation of public health practice. The major objective of the study is to analyse the rate of
infections of the people in Mullanginavilai Panchayat during their behavioural risk factors like poor sanitation.

\section{MATERIALS AND METHODS}

A two-month descriptive study was carried out among the 50 residents in Mullanginavilai village in Karungal, Kanyakumari district, Tamilnadu, India. The Socioeconomic status (Age, Sex, Occupation, Income); Health status (Acute disease, Chronic disease); and Drainage facilities has been obtained.

\section{RESULTS}

The socio-economic and health survey of the community showed that $28 \%$ of the population have no job at all and $24 \%$ among them are economically poor class. $24 \%$ of the respondents have chronic disease. Anaemia was highly prevalent and severe with $38 \%$ severe anaemia, was strongly concentrated in children and undergone treatment. Infection with malaria parasite was the next highly prevalent, which was about $16 \%$. Other amoebic dysentery and skin infection is milder about $12 \%$. In the community, $50 \%$ of the people had the habit of taking anti-helminthic drugs for every 6 months. Others were not particularly children.

\section{CONCLUSION}

The study showed significantly high level of contamination of soil and water due to parasites. This might be a reason for infections among the neighbouring community people.

\section{KEYWORDS}

Mullanginavilai Village, Health Surveillance, Anaemia, Malaria Parasite, Amoebic Dysentery, Anti-Helminthic Drugs.

HOW TO CITE THIS ARTICLE: Ravirajan M, Anandh SJV, Mary BL, et al. Public health surveillance of infections and behavioural risk factors like poor sanitation in a changing environment. J. Evolution Med. Dent. Sci. 2018;7(15):1901-1904, DOI: $10.14260 /$ jemds/2018/428

\section{BACKGROUND}

Public health surveillance is the continuous, systematic collection, analysis and interpretation of health-related data needed for the planning, implementation and evaluation of public health practice.(1) Such surveillance can serve as an early warning system for impending public health

'Financial or Other Competing Interest': None.

Submission 02-03-2018, Peer Review 28-03-2018,

Acceptance 02-04-2018, Published 09-04-2018.

Corresponding Author:

Dr. Revathi P. Shenoy,

Associate Professor,

Department of Biochemistry,

Kasturba Medical College,

Manipal Academy of Higher Education, Manipal, Karnataka, India

E-mail: revathi.shenoy@manipal.edu

DOI: $10.14260 /$ jemds $/ 2018 / 428$

\section{(c) (i) $(9)$}

emergencies; document the impact of an intervention or track progress towards specified goals; and monitor and clarify the epidemiology of health problems, to allow priorities to be set and to inform public health policy and strategies.(2)

The health care needs of the world's population are likely to undergo dramatic changes due to the ongoing demographic transition. Non-communicable diseases (NCDs) such as diabetes, cancer, depression and heart disease are rapidly replacing infectious diseases and malnutrition as the leading causes of disability and premature death. Eighty percent of total deaths due to non-communicable diseases occur in the low income countries. (3) Men and women are equally affected. Cancer, cardiovascular diseases (CVD) and diabetes are becoming of serious concern, accounting for 52 percent of deaths and 38 percent of disease burden in the WHO South-East Asia Region (SEAR). With the current trends 
the top five causes of disability adjusted life years (DALYs) lost in 2020 are likely to be ischaemic heart disease, unipolar major depression, road traffic injuries, cerebrovascular diseases and chronic obstructive lung disease.(4) It has been estimated that a 2 percent reduction in chronic diseases death rates per year globally could result in saving about 36 million premature deaths by the year 2015.(5)

While mortality due to communicable diseases is decreasing and that for non-communicable diseases is rising at a very rapid pace.(6) The health policy makers are faced with the burden of providing resources for the control and prevention of both the existing communicable diseases and the increasing number of non-communicable diseases. This becomes difficult since the programmes for prevention and control of communicable diseases drain the meagre resources.(7) It is therefore not surprising that India has faced a serious handicap while planning and initiating programmes and activities to combat non-communicable diseases including cardiovascular diseases. ${ }^{(8)}$

Helminths or worm infestations refer to worms that live as parasites in the human body and are a fundamental cause of disease associated with health and nutrition problems beyond gastrointestinal tract disturbances. ( 9 )

Globally, over 3.5 billion people are infected with intestinal worms, of which 1.47 billion are with roundworm, 1.3 billion people with hookworm and 1.05 billion with whipworm.

School children aged 5 - 15 years suffer the highest infection rate and worm burden that attributes to poor sanitation and hygiene.(10) About 400 million school-age children are infected with roundworm, whipworm and hookworm worldwide, a large proportion of who are found in the East-Asia region.(11)

Parasites consume nutrients from children they infect, thus retarding their physical development. They destroy tissues and organs, cause abdominal pain, diarrhoea, intestinal obstruction, anaemia, ulcers and other health problems.(12)

All of these consequences of infection can slow cognitive development and thus impair learning. De-worming school children by anthelmintic drug treatment is a curative approach for expelling the heavy worm load. However, drug therapy alone is only a short-term measure of reducing worm infection and reinfection is frequent.(13) Control measures through improved sanitation, hygiene and de-worming are needed to prevent infection and re-infection.(14)

UNICEF has supported many governments in this (and other) region to assist in the provision of water supply and sanitary facilities and intensive hygiene education in many schools through the Water, Environment and Sanitation (WES) Programme.(15)

The UNICEF supported school sanitation and hygiene education (SSHE) programme, and other programmes could effectively enhance behaviour change in children to break the routes of worm transmission and other water-borne diseases.(16)

The major objective of the study is to analyse the rate of infections of the people in Mullanginavilai Panchayat during their behavioural risk factors like poor sanitation.

\section{MATERIALS AND METHODS}

\section{Study Population}

A descriptive study was carried out in Mullanginavilai village in Karungal, Tamilnadu, India. Mullanginavilai is the smaller village and is located just off the south coast of mainland Nagercoil. Mullanginavilai is almost entirely rural and the population survives on daily wages like farming, construction works etc.

The staple foods are fish, vegetables and rice. Meat and chicken is eaten rarely and large fishes are relatively expensive. Small fish, legumes and vegetables are eaten more commonly.

\section{Data Collection}

Data was collected by providing questionnaire scripting of state-added questions. The core portion of the questionnaire takes an average of 15 to 20 minutes to conduct for each individual.

In August - September 2015, a detailed health survey was conducted among the 50 residents in the village. The socioeconomic status (Age, Sex, Occupation, Income); Health status (Acute disease, Chronic disease); and Drainage facilities has been obtained. The obtained result was to be tabulated, analysed and discussed with available scientific literature.

\section{RESULTS}

An investigation on the prevalent of health effects among different sources of the dumping yard and surroundings were conducted. A survey on the socio-economy and health of the neighbouring community was also conducted.

The socio-economic and health survey of the community showed that $28 \%$ of the population have no job at all and $24 \%$ among them are economically poor class. $24 \%$ of the respondents have chronic disease.

The population in this study were mainly children about $56 \%$ followed by adults and old age which was about $32 \%$ and $12 \%$ respectively. The sex ratio is 19: 31 (Male: Female) out of 50. The detailed results of the socio-economic parameters were shown in Table 1 .

Anaemia was highly prevalent and severe with 38\% severe anaemia strongly concentrated on children and undergone treatment. Infection with malaria parasite was the next highly prevalent which was about $16 \%$, other amoebic dysentery and skin infection is milder about $12 \%$. In the community $50 \%$ of the people had the habit of taking antihelminthic drugs for every 6 months, others were not particularly children. The results are tabulated in Table 2 .

Most of the residents around the dumping yard are victimised with unending problem such as mosquito/ fly menace, contaminations of well by wasted (by birds) and of foul smell (Table 2).

\begin{tabular}{|c|c|c|c|}
\hline Social & Parameter & Number & Percentage \\
\hline \multirow{2}{*}{ Sex Wise } & Male & 19 & 38 \\
\hline & Female & 31 & 62 \\
\hline \multirow{3}{*}{ Age Wise } & $0-15$ & 28 & 56 \\
\hline & $15-50$ & 16 & 32 \\
\hline & $51-75$ & 6 & 12 \\
\hline \multirow{5}{*}{ Occupation } & No job & 14 & 28 \\
\hline & Coolie & 8 & 16 \\
\hline & Business & & \\
\hline & Student & 28 & 56 \\
\hline & Others & & \\
\hline \multirow{3}{*}{ Economic Status } & Poor & 12 & 24 \\
\hline & Moderate & 32 & 64 \\
\hline & Rich & 6 & 12 \\
\hline
\end{tabular}




\begin{tabular}{|c|c|c|c|}
\hline & & Number & Percentage \\
\hline \multirow{6}{*}{$\begin{array}{c}\text { Acute Diseases } \\
\text { (During the Past } \\
\text { One Year) }\end{array}$} & Skin infections & 6 & 12 \\
\hline & Allergy & 7 & 14 \\
\hline & $\begin{array}{l}\text { Breathing } \\
\text { problem }\end{array}$ & 4 & 8 \\
\hline & Fever (malaria) & 8 & 16 \\
\hline & Diarrhoea & 6 & 12 \\
\hline & Anaemia & 19 & 38 \\
\hline \multirow{2}{*}{ Chronic Disease } & Cancer & 0 & \\
\hline & Diabetic & 12 & 24 \\
\hline Deworming & Every 6 months & 25 & 50 \\
\hline Sanitation & \begin{tabular}{|c} 
Near to toilet- \\
Yes
\end{tabular} & 32 & 64 \\
\hline Open Well & No & 18 & 36 \\
\hline \begin{tabular}{|c}
$\begin{array}{c}\text { Drinking Water } \\
\text { (Boiling) }\end{array}$ \\
\end{tabular} & Yes & 36 & 72 \\
\hline \multirow{3}{*}{$\begin{array}{c}\text { Problems Posed } \\
\text { by Dumping } \\
\text { Yard }\end{array}$} & $\begin{array}{l}\text { Mosquito/ fly } \\
\text { menace }\end{array}$ & 39 & 78 \\
\hline & Foul smell & 41 & 82 \\
\hline & $\begin{array}{c}\text { Contamination } \\
\text { by well by } \\
\text { wastes (by } \\
\text { birds) }\end{array}$ & 22 & 44 \\
\hline
\end{tabular}
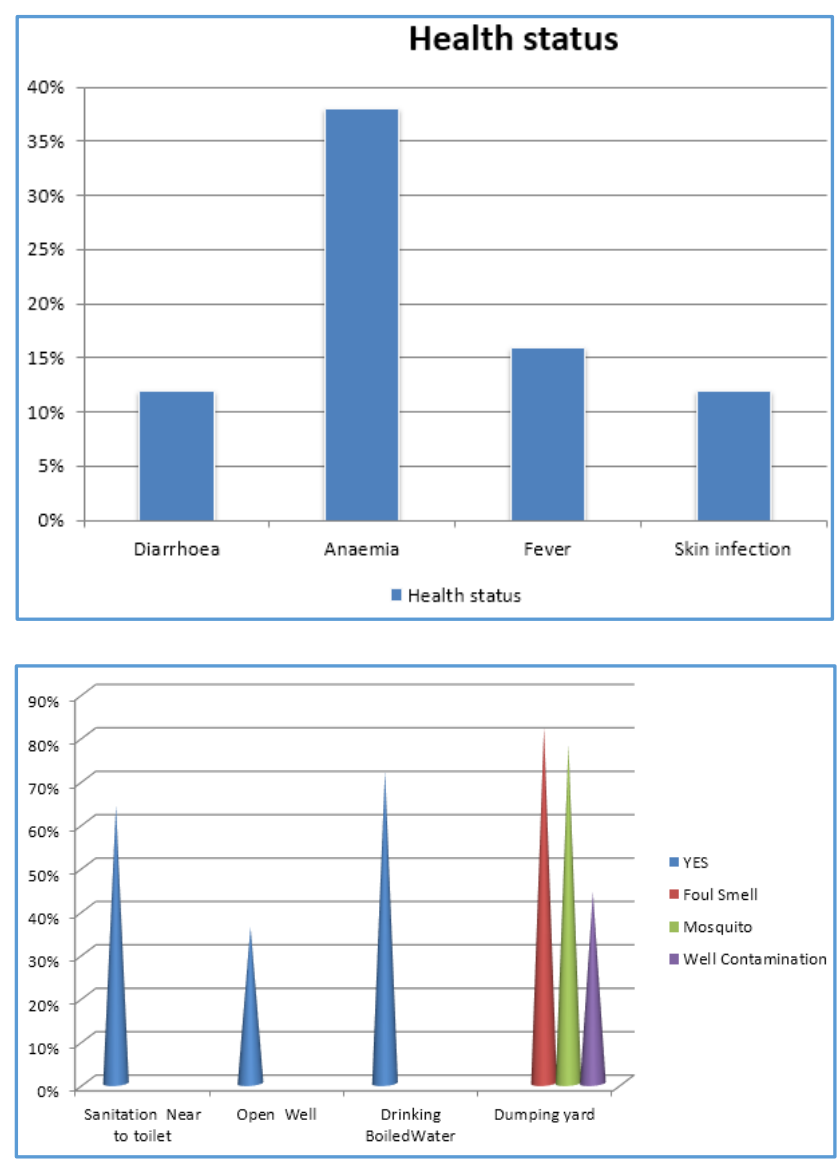

Chart 1 and 2. Showing Health Status and Sanitation

\section{DISCUSSION}

Population growth and economic development have brought increasing amounts of solid waste and the quantity is increasing day by day. The disposal of waste in open landfill is the easiest method, but it results in a series of adverse health effects to the interacting community including fringe area people.
The leachate from landfill deteriorates the quantity of the drinking water in the near vicinity. The relation between several vector-borne diseases and waste dumping site are well established. However, studies on the possible role of dumping yard in the propagations of pathogen are least explored. The present study has exposed the severity of the situation, especially of parasitic threat.(17)

A total of eight (36\%) people have open wells near dumping yard, and there was a $44 \%$ chance the well was contaminated with the wastes. Several reports are available in agreement with present finding.

Although, it is generally believed that the rates of other diseases will decrease following improvements in water and sanitation. There have been no systematic reviews of this. The health impact of water and sanitation interventions of the disease: ascariasis (Ascaris lumbricoides), diarrhoeal diseases (including measures of nutritional status and child survival), dracunculiasis (Dracunculus medinensis), hookworm infection (Ancylostoma duodenale and Necator americanus), Schistosomiasis (Schistosoma haematobium and S. mansoni).

They are widespread in developing countries or because they constitute serious problems where they exist or both. All developing countries are affected by diarrhoeal diseases and ascariasis. The other four diseases are somewhat more restricted in their range; although, they are all prevalent in some developing countries except dracunculiasis, which only occurs in parts of Africa and Asia.(18)

These diseases also illustrate the variety of mechanisms through which improved water and sanitation can promote health. Four basic aspects were considered: Sanitation (i.e. human excreta disposal), water quality, personal hygiene and domestic hygiene.(19)

Personal hygiene refers to water used for cleaning the body including water for the face, hands and eyes; domestic hygiene refers to water used to keep the home clean (e.g. food, utensils and floors).

Each disease is affected by one or more of these interventions. For example- providing safe, potable sources of drinking water will probably prevent transmission of dracunculiasis, while using larger quantities of water for personal hygiene will probably interrupt the spread of trachoma. The incidence, prevalence and/or severity of all these diseases are reduced by water and sanitation interventions. $(20)$

Anthelmintic treatment can be aimed at particular occupational or age groups that are thought to represent those most at risk of acquiring heavy infection and subsequently developing severe morbidity. This is, for instance, the basis for school-based health programmes aimed at deworming children of STHs and schistosomiasis.(21)

In this target population, treatment is administered to all individuals regardless of whether or not they are patently infected. In areas of substantial endemicity and according to infection prevalence thresholds, community (mass) treatment is recommended. Other strategies include mass screen and treat (targeting selective treatment to those with patent and detectable infection at the point of screening) or treating individual cases in clinical as opposed to community settings.(22) 


\section{CONCLUSION}

The study showed significantly high level of contamination of soil and water due to parasites. This might be a reason for infections among the neighbouring community people.

The long-term control and elimination of these helminth diseases will also depend on improved control tools such as more effective anthelmintics and/ or vaccines, control of vectors, intermediate hosts or reservoirs, improved diagnostics and surveillance tools, sanitation, hygiene, socioeconomic improvement and environmental sustainability of the interventions. If they become available, antiparasitic vaccines could have a major impact on sustained control of helminth diseases and could be combined with MDA to provide complementary approaches that may improve control and reduce selection for drug resistance.

Vector control, where applicable, practical and cost effective remains a useful addition to chemotherapy-based intervention that can lead to marked reductions in transmission and reinfection rates. Efforts to integrate various MDA programmes may bring at first logistical challenges, but in the long-term benefits to the overall impact of intervention strategies.

Though, the study is limited with small sample size and short span of study period, the data is significant, both from academic and public points of view.

\section{REFERENCES}

[1] Stoll NR. On endemic hookworm, where do we stand today? Exp Parasitol 1962;12:241-52.

[2] Hotez PJ. The national institutes of health roadmap and the developing world. J Investig Med 2004;52(4):246-7.

[3] Hotez PJ, Brooker S, Bethony JM, et al. Hookworm infection. N Engl J Med 2004;351(8):799-807.

[4] De Silva NR, Brooker S, Hotez PJ, et al. Soil-transmitted helminth infections: updating the global picture. Trends Parasitol 2003;19(12):547-51.

[5] Hotez PJ. China's hookworms. China Q 2002;172:102941.

[6] Yadla S, Sen HG, Hotez PG. An epidemiological study of ancylostomiasis in a rural area of Kanpur district Uttar Pradesh, India. Indian J Public Health 2003;47(2):5360.

[7] Hotez PJ. Hookworm in the Americas: progress in the development of an anti-hookworm vaccine. In: de Quadros CA, (eds). Vaccines: preventing disease and protecting health. Washington (D.C.): Pan American Health Organization; 2003:213-20.

[8] Montresor A, Crompton DWT, Gyorkos TW, et al. Helminth control in school-age children: a guide for managers of control programmes. Geneva: World Health Organization; 2002.
[9] Bethony J, Chen J, Lin S, et al. Emerging patterns of hookworm infection: influence of aging on the intensity of Necator infection in Hainan Province, People's Republic of China. Clin Infect Dis 2002;35(11):1336-44.

[10] Olatunde BO, Onyemelukwe GC. Immunosuppression in Nigerians with hookworm infection. Afr J Med Med Sci 1994;23(3):221-5.

[11] Williamson AL, Brindley PJ, Knox DP, et al. Digestive proteases of blood-feeding nematodes. Trends Parasitol 2003;19(9):417-23.

[12] Stoltzfus RJ, Dreyfuss ML, Chwaya HM, et al. Hookworm control as a strategy to prevent iron deficiency. Nutr Rev 1997;55(6):223-32.

[13] Brooker S, Peshu N, Warn PA, et al. The epidemiology of hookworm infection and its contribution to anaemia among pre-school children on the Kenyan coast. Trans R Soc Trop Med Hyg 1999;93(3):240-6.

[14] Sakti H, Nokes C, Hertanto WS, et al. Evidence for an association between hookworm infection and cognitive function in Indonesian school children. Trop Med Int Health 1999;4(5):322-34.

[15] Bundy DA, Chan MS, Savioli L. Hookworm infection in pregnancy. Trans R Soc Trop Med Hyg 1995;89(5):5212.

[16] Alam N, Wojtyniak B, Henry FJ, et al. Mothers' personal and domestic hygiene and diarrhoea incidence in young children in rural Bangladesh. Int $\mathrm{J}$ Epidemiol 1989;18(1):242-7.

[17] Chandler AC. A comparison of helminthic and protozoan infections in two Egyptian villages two years after the installation of sanitary improvements in one of them. Am J Trop Med Hyg 1954;3(1):59-73.

[18] Scott JA, Barlow CH. Limitations to the control of helminth parasites in Egypt by means of treatment and sanitation. Am Journal of Hygiene 1938;27:619-48.

[19] Shiffman MA, Schneider R, Faigenblum JM, et al. Field studies on water, sanitation and health education in relation to health status in central America. Progress in water technology 1978;11:143-50.

[20] Snyder JD, Merson MH. The magnitude of the global problem of acute diarrhoeal disease: a review of active surveillance data. Bull World Health Organ 1982;60(4):605-13.

[21] Stanton BF, Clemens JD. Socioeconomic variables and rates of diarrhoeal disease in urban Bangladesh. Transactions of the Royal Society o1 Tropical Medicine and Hygiene 1987;81:278-82.

[22] Misra KK. Safe water in rural areas. An experiment in promoting community participation in India. International Journal of Health Education 1975;18(1):53-9. 